\title{
The Problems of project management software implementation in construction corporations
}

\author{
Pavel Kagan ${ }^{1 *}$, Anna Naumova ${ }^{1}$, and Yuriy Vilman ${ }^{1,}$ \\ ${ }^{1}$ Moscow State University of Civil Engineering, 129337, Yaroslavskoe shosse, 26, Moscow, Russia
}

\begin{abstract}
The article is devoted to the main problems facing many companies, implementing software project management activities have been working construction corporation. The company transferred the task performing the activities for the implementation, as well as its purpose. Revealed rules that must be followed to achieve the best results in the implementation of software project management.
\end{abstract}

\section{Introduction}

Construction corporations are gradually coming out of the beginning stage of ITdevelopment. Herewith, the main role in developing of Russian construction complex is acting by a construction companies, which are not only possessing of a significant investment potential for making a huge projects and programs of a branch development, but also interested in acceleration of a science-technical progress, qualitative changes of a branch complex and development of innovative technologies on different levels of a branch management. It is required the newest software for project management in order to automatize their activities. Implementing such a software in construction companies, it is necessary to take into consideration that it is possible to face many problems on any stage that can lead to failures from both of sides.

\section{The Problems of project management software implementation}

On practice, the project is a totality of an actions directed on the achievement of the goal to create some complicated system with specified characteristics of quality in limited deadlines and on limited quantity of resources.

It is impossible to make qualitative planning, realize efficient control and operative correction of a plan without the using of special software because of a big volume of planned actions, complexity of a distributions and plan optimization methods. The technology of network planning and management is in the basis of using software. The primary aspects of this technology were created in $70 \mathrm{~s}$.

\footnotetext{
* Corresponding author: kagan@mgsu.ru
} 
Nowadays, the market of software products is full of different facilities that realize network-planning methods - from huge professional systems to the systems let you dispose of your working time, financials and resource allocations efficiently [4-7].

The main tasks of the company, which implements the project management methods, are:

- The automatization of business-processes in a corporation

- To set the software under the certain corporation

- The integration with using software

- Input of reference or analytical information

- The training of a corporation staff

- The main goal of a scientific organization of a labor is to increase the efficiency of work in organization. It means:

- More rational using of resources

- Increasing of product quality and quality of consumers service

- Reaching of higher labor producing; reduction of costs

The main problems of a software implementation:

- Unclear formulation of the task from customer

The common problem that is occurring in implementation of software is to find out all the tasks and to realize the solution. Such a problem can occur because of misunderstanding of work processes in corporation and all accompanying structures.

- The necessity of particular reorganization of structure and organization activities.

Before beginning to implement the automatization systems into the corporation, there is necessary to make particular reorganization of its structure and business management technology. So, one of the sages of implementation is full and reliable examination of all working aspects in corporation.

- The need to change the working technology with information and businessmanagement principles.

Efficiently built informational system cannot deal without some changes of eventual planning technology.

- The resistance of employees.

With the implementation of new software, it can be resistance of employees in most of cases. It is a serious barrier for consultants and it can cause real delays of implementation. This problem is occurring because of several human factors: usual fear of innovations, conservatism, apprehension of losing the workplace or your indispensability, fear of responsibility [1].

- Temporary increase of employees load.

Workers have to learn new knowledges and technologies. During the experience exploitation and with transition to industrial exploitation of the system, it is necessary to make business as in new system as by traditional ways during some time.

After the implementation of new software into a longtime team, their earning capacity is decreasing sharply. It is over $60 \%$ of the original level of working team earning capacity. After the recovery period, the period of original level excessing is starting, it is over 10$20 \%$ more than original level. Each stage can go for different time in different corporations [2].

- The formation of skilled team of an implementation and system accompaniment, head of a team.

Some little working group (3-6 person) is starting to be formatted. The group is starting to learn full-max education of working with the system, than a huge part of implementation and accompaniment work is lying on this group. Especially important problem is choosing of the head of such group and administrator of the system. The head, excepting the 
knowledges of base computer technologies, must possess of the knowledges in the sphere of business making and project management [3]. (Figure 1,2).

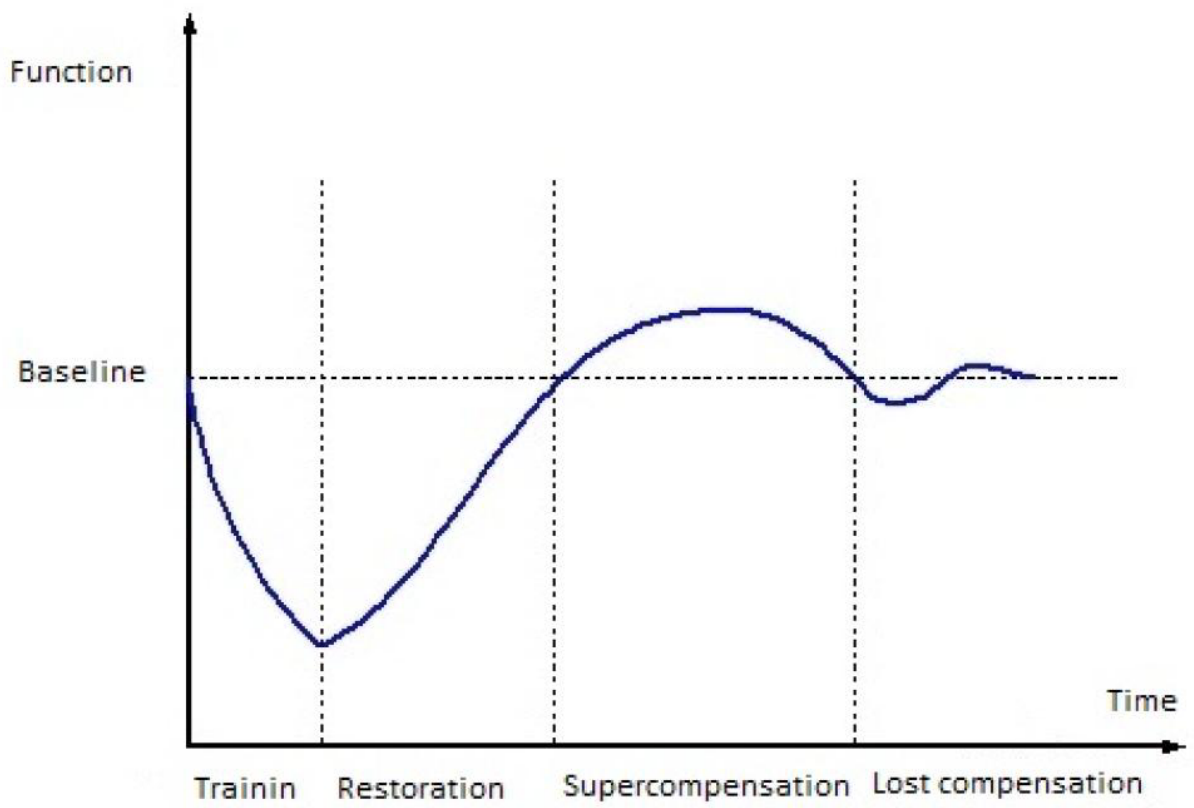

Fig. 1. Schedule changes in the load of employees during the implementation phase.

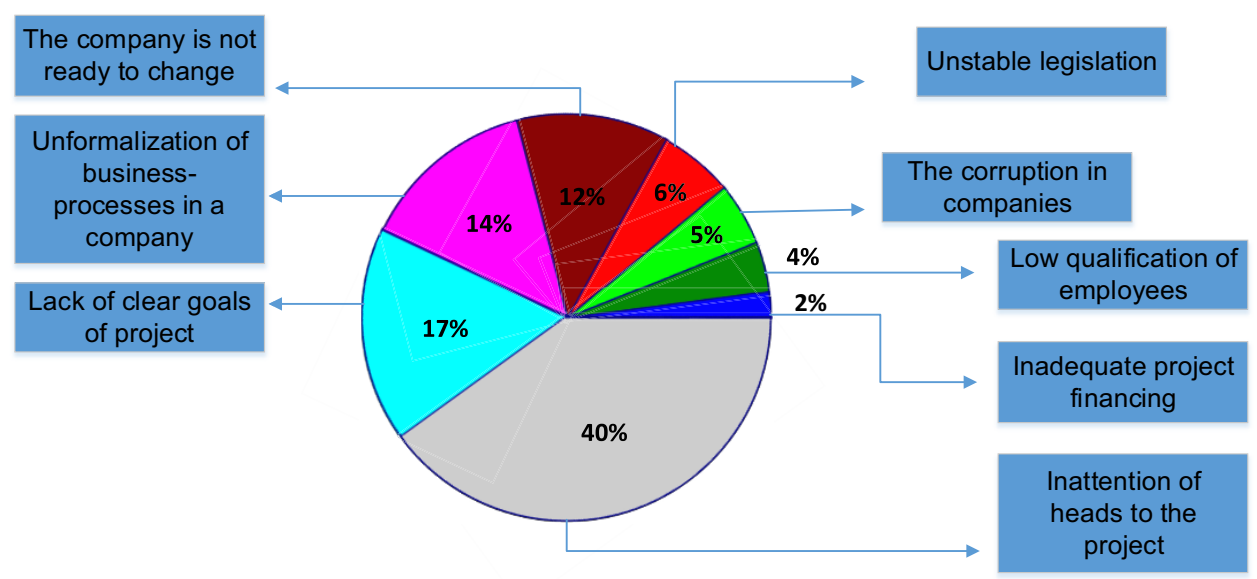

Fig. 2. Diagram reasons for unsuccessful implementation. 


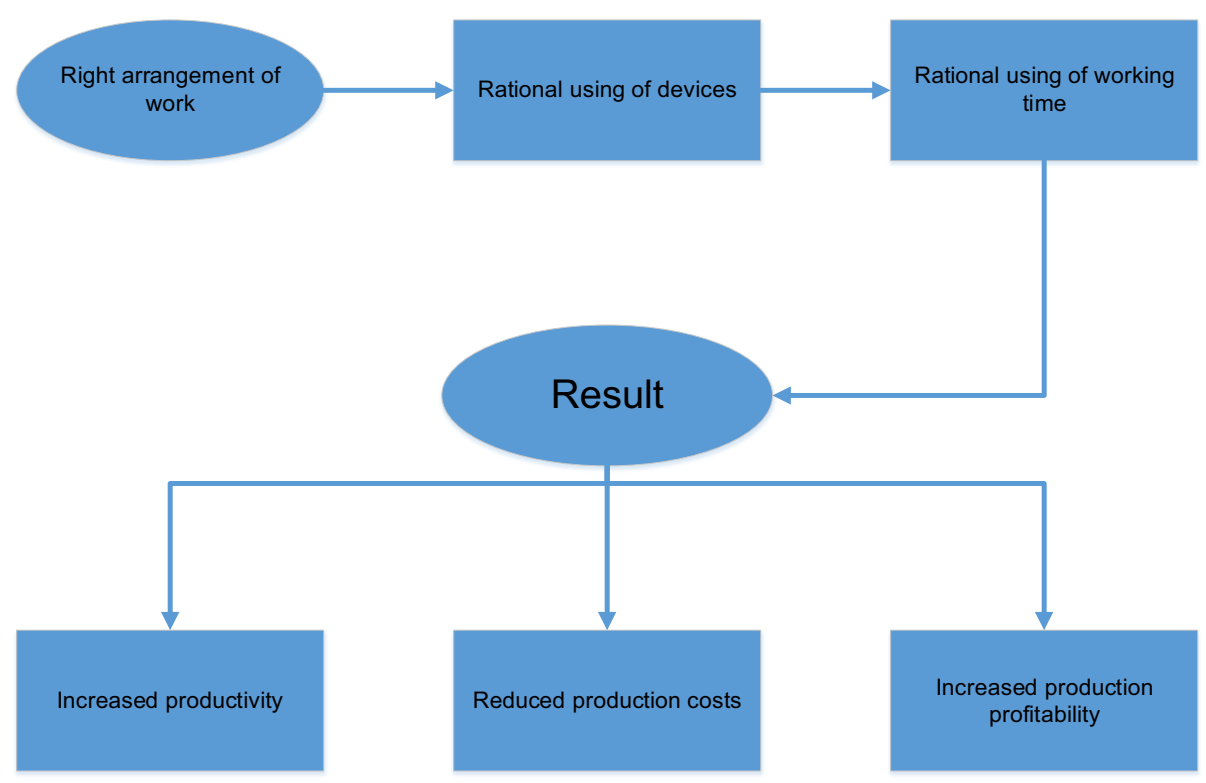

Fig. 3. The scheme rules software implementation in the organization.

\section{Conclusions}

The reasons that can cause unsuccessful implementation:

1.Inadequate project financing

2. Low qualification of employees

3. The corruption in companies

4. Unstable legislation

5. The company is not ready to change

6. Unformalization of business-processes in a company

7. Lack of clear goals of project

8. Inattention of heads to the project.

The rules to follow in order to reach the best result of a project management software implementation:

1. Right arrangement of work

2. Rational using of devices

3. Rational using of working time

\section{References}

1. M.L. Once, Project management. Basics of project management: the textbook, (KNORUS, Moscow, 2006)

2. D.V. Bogdanov, O.V. Kazantsev, Information technology, 2(22) (1997)

3. D.A. Novikov, Introduction to the institutional arrangements of project management, (PMSOFT, 2007)

4. B.K. Pavel, V.G. Kulikov, Applied Mechanics and Materials, 951-954 (2013)

5. V.G. Kulikov, P.B. Kagan, L.V. Sukneva, Applied Mechanics and Materials, 405-408 (2013)

6. P.B. Kagan, T.A. Barabanova, Computing in Civil and Building Engineering, 22322237 (2014) 
7. K.E. Anatolevna , K.P. Borisovich, International Journal of Applied Engineering Research, 10(23), 43456-43460 (2015)

8. M. Mazlum, A. F. Güneri, Procedia - Social and Behavioral Sciences, 210(2), 348-357 (2015)

9. F. Backlund, D. Chronéer, E. Sundqvist, Procedia - Social and Behavioral Sciences, 119(19), 837-846 (2014)

10. M. Lazarevska, M., Cvetkovska, M., Knezevic, (...), V. Murgul, N. Vatin, Applied Mechanics and Materials, 627, 276-282 (2014)

11. Z. Radovanović, R. Sinđić Grebović, S. Dimovska, N. Serdar, N. Vatin, V. Murgul, Procedia Engineering, 117, 870-878 (2015)

12. J. Ćetković, S. Rutešić, M. Zarković, M. Knežević, , N.Vatin, Procedia Engineering, 117 (1), 780-790 (2015)

13. S. Rutešić, J. Ćetković, M. Žarcković, M. Knežević, N. Vatin, Procedia Engineering, 117 (1), 905-915 (2015)

14. A. Serpell, X. Ferrada, L. Rubio, S. Arauzo, Procedia - Social and Behavioral Sciences, 194 (2), 201-210 (2015) 